\title{
BMJ Open Demographics, practice patterns and long- term outcomes of patients with non-ST- segment elevation acute coronary syndrome in the past two decades: the CREDO-Kyoto Cohort-2 and Cohort-3
}

Yasuaki Takeji, ${ }^{1}$ Hiroki Shiomi, ${ }^{1}$ Takeshi Morimoto (D) , ${ }^{2}$ Yusuke Yoshikawa, ${ }^{1}$ Ryoji Taniguchi, ${ }^{3}$ Yukiko Mutsumura-Nakano, ${ }^{1}$ Ko Yamamoto, ${ }^{1}$ Kyohei Yamaji, ${ }^{4}$ Junichi Tazaki, ${ }^{1}$ Satoru Suwa, ${ }^{5}$ Moriaki Inoko, ${ }^{6}$ Teruki Takeda, ${ }^{7}$ Manabu Shirotani, ${ }^{8}$ Natsuhiko Ehara, ${ }^{9}$ Katsuhisa Ishii, ${ }^{10}$ Tsukasa Inada, ${ }^{11}$ Tomoya Onodera, ${ }^{12}$ Eiji Shinoda, ${ }^{13}$ Takashi Yamamoto, ${ }^{14}$ Takashi Tamura, ${ }^{15}$ Kenji Nakatsuma, ${ }^{16}$ Hiroki Sakamoto, ${ }^{17}$ Kenji Ando, ${ }^{4}$ Yoshiharu Soga, ${ }^{18}$ Yutaka Furukawa, ${ }^{9}$ Yukihito Sato, ${ }^{3}$ Yoshihisa Nakagawa, ${ }^{14}$ Kazushige Kadota, ${ }^{19}$ Tatsuhiko Komiya, ${ }^{20}$ Kenji Minatoya, ${ }^{21}$ Takeshi Kimura (D) , ${ }^{1}$ the CREDO-Kyoto PCI/CABG Registry Cohort-2 and the CREDO-Kyoto PCI/CABG Registry Cohort-3 Investigators

To cite: Takeji Y, Shiomi H, Morimoto T, et al.

Demographics, practice patterns and long-term outcomes of patients with non-ST-segment elevation acute coronary syndrome in the past two decades: the CRED0-Kyoto Cohort-2 and Cohort-3. BMJ Open 2021;11:e044329. doi:10.1136/ bmjopen-2020-044329

- Prepublication history and additional material for this paper is available online. To view these files, please visit the journal online (http://dx.doi.org/10. 1136/bmjopen-2020-044329).

Received 31 August 2020 Revised 08 December 2020 Accepted 08 February 2021

Check for updates

(c) Author(s) (or their employer(s)) 2021. Re-use permitted under CC BY-NC. No commercial re-use. See rights and permissions. Published by BMJ.

For numbered affiliations see end of article.

Correspondence to Professor Takeshi Kimura; taketaka@kuhp.kyoto-u.ac.jp

\section{ABSTRACT}

Objectives To evaluate patient characteristics and long-term outcomes in patients with non-ST-segment elevation acute coronary syndrome (NSTEACS) in the past two decades.

Design Multicenter retrospective study.

Setting The Coronary REvascularization Demonstrating Outcome Study in Kyoto (CREDO-Kyoto) percutaneous coronary intervention (PCI)/coronary artery bypass grafting (CABG) Registry Cohort-2 (2005-2007) and Cohort-3 (2011-2013).

Participants 3254 patients with NSTEACS who underwent first coronary revascularisation.

Primary and secondary outcome measures The primary outcome was all-cause death. The secondary outcomes were cardiovascular death, cardiac death, sudden cardiac death, non-cardiovascular death, noncardiac death, myocardial infarction, definite stent thrombosis, stroke, hospitalisation for heart failure, major bleeding, any coronary revascularisation and target vessel revascularisation.

Results Patients in Cohort- 3 were older and more often had heart failure at admission than those in Cohort-2. The prevalence of $\mathrm{PCl}$, emergency procedure and guidelinedirected medical therapy was higher in Cohort-3 than in Cohort-2. In patients who received $\mathrm{PCl}$, the prevalence of transradial approach, drug-eluting stent use and intravascular ultrasound use was higher in Cohort-3 than in Cohort-2. There was no change in 3-year adjusted mortality risk from Cohort-2 to Cohort-3 (HR 1.00, 95\% Cl 0.83 to $1.22, p=0.97)$. Patients in Cohort-3 compared with those in Cohort-2 were associated with lower adjusted risks for stroke (HR 0.65, 95\% $\mathrm{Cl} 0.46$ to $0.92, \mathrm{p}=0.02$ ) and any coronary revascularisation (HR $0.76,95 \% \mathrm{Cl} 0.66$ to $0.87, p<0.001$ ), but with higher risk for major bleeding (HR 1.25, 95\% Cl 1.06 to 1.47, $p=0.008$ ). The unadjusted

\section{Strengths and limitations of this study}

The present study is the first study evaluating changes in demographics, clinical practices and long-term clinical outcomes in patients with non-ST-segment elevation acute coronary syndrome (NSTEACS) enrolled beyond 2010 (Cohort-3) compared with those enrolled before 2010 (Cohort-2).

- The 3-year adjusted risk of patients in Cohort-3 relative to those in Cohort-2 was not significantly different for all-cause death.

- Patients in Cohort-3 as compared with those in Cohort-2 were associated with lower risks for definite stent thrombosis, stroke and any coronary revascularisation, but with higher risk for major bleeding.

- This study was a historical comparison and should result in systematic differences in selection of patients and acquisition of outcomes.

risk for definite stent thrombosis was lower in Cohort-3 than in Cohort 2 (HR 0.29, 95\% Cl 0.11 to $0.67, \mathrm{p}=0.003$ ). Conclusions In the past two decades, we did not find improvement for mortality in patients with NSTEACS. We observed a reduction in the risks for definite stent thrombosis, stroke and any coronary revascularisation, but an increase in the risk for major bleeding.

\section{INTRODUCTION}

Non-ST-segment elevation acute coronary syndrome (NSTEACS), consisting of nonST-segment elevation myocardial infarction (NSTEMI) and unstable angina (UA), has 
been one of the main causes of death from cardiovascular disease. ${ }^{1}$ Several studies also demonstrated that the early mortality of patients with NSTEACS have improved from 1990s to 2000s. ${ }^{2-4}$ However, there was a scarcity of studies evaluating the long-term clinical outcomes in patients with NSTEACS enrolled beyond 2010 compared with those enrolled before $2010{ }^{5}$ Therefore, we aimed to evaluate changes in demographics, practice patterns and long-term clinical outcomes in patients with NSTEACS in the past two decades using data from a series of large Japanese cohorts of patients who underwent first coronary revascularisation enrolled in 2005-2007 and 2011-2013.

\section{METHODS}

\section{Study population}

The Coronary REvascularization Demonstrating Outcome Study in Kyoto (CREDO-Kyoto) percutaneous coronary intervention (PCI)/coronary artery bypass grafting (CABG) Registry Cohort-2 and Cohort-3 are a series of physician-initiated, non-company sponsored, multicentre registry enrolling consecutive patients who underwent first coronary revascularisation, either PCI or isolated CABG. Cohort-2 enrolled patients between January 2005 and December 2007 among 26 centres in Japan after the introduction of drug-eluting stents (DES) in 2004 (online supplemental appendix A). ${ }^{6}$ Cohort-3 enrolled patients between January 2011 and December 2013 among 22 centres in Japan after approval of the new-generation DES in 2010 (online supplemental appendix A). We enrolled a total of 30257 consecutive patients who had undergone first coronary revascularisation with PCI or isolated CABG in Cohort-2 ( $\mathrm{N}=15330)$ and Cohort-3 $(\mathrm{N}=14927)$. The annual volume of first coronary revascularisation procedures for stable coronary artery disease and acute coronary syndrome in each participating centre was described in online supplemental table 1 . There were 3386 patients with NSTEACS, after excluding patients with refusal for study participation, patients with stable coronary artery disease and patients with ST elevation myocardial infarction (STEMI). To make the two cohorts comparable, we further excluded 124 patients in Cohort-2 who were enrolled from four cardiology divisions and five cardiovascular surgery divisions not participating in Cohort-3, and 8 patients in Cohort-3 who were enrolled from one cardiovascular surgery division not participating in Cohort-2. Finally, we retrieved 3254 patients with NSTEACS for the current study (Cohort-2: 1683 patients and Cohort-3: 1571 patients) from 22 centres (both PCI and CABG available: 15 centres and only PCI available: 7 centres) (figure 1).

The relevant institutional review boards at all participating hospitals approved the study protocols, and we performed the study in accordance with the Declaration of Helsinki. Written informed consent for both registries were waived because of the retrospective nature of the study; however, we excluded those patients who refused participation in the study when contacted at follow-up. This strategy is concordant with the guidelines of the Japanese Ministry of Health, Labor and Welfare.

\section{Definitions and clinical outcome measures}

NSTEACS consisted of NSTEMI and UA. NSTEMI was defined as acute coronary syndrome (ACS) other than STEMI, with elevating cardiac biomarkers, consisting of at least a value exceeding the upper reference limit for troponin, or $>3 \times$ of the upper reference limit for creatine kinase MB (CK-MB). UA was defined as ACS meeting
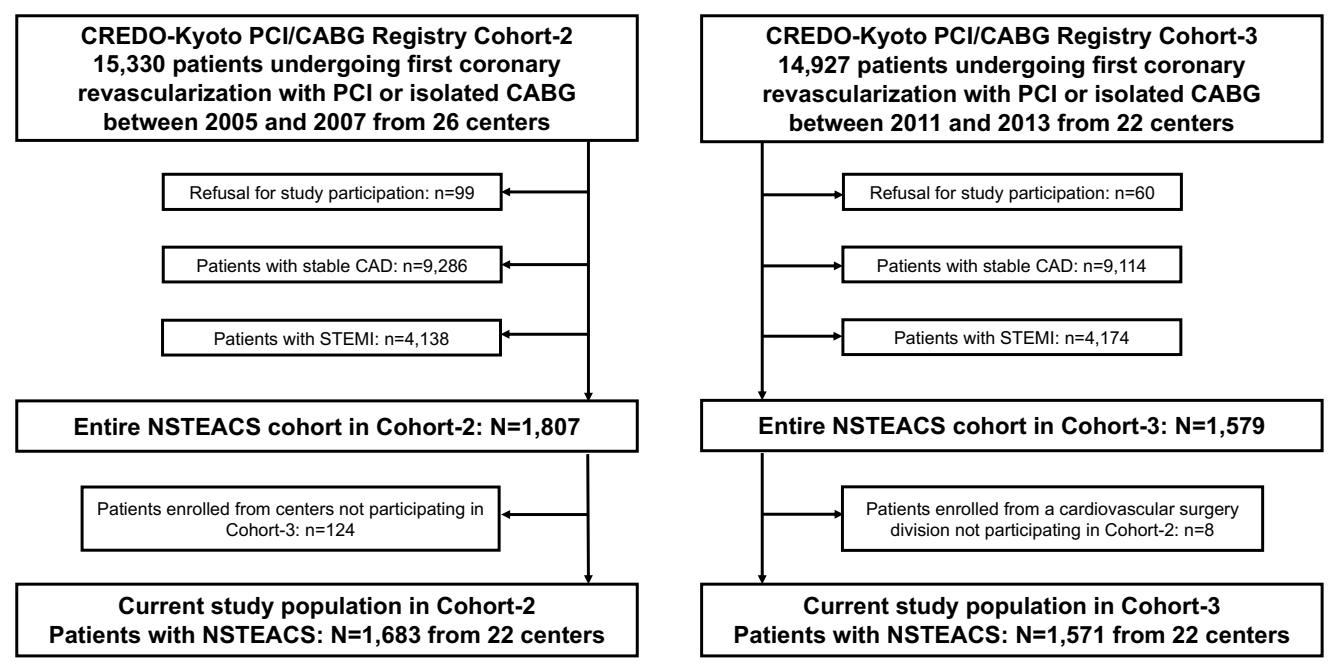

Figure 1 Study flowchart. CABG, coronary artery bypass grafting; CAD, coronary artery disease; CREDO-Kyoto, Coronary REvascularization Demonstrating Outcome study in Kyoto; NSTEACS, non-ST-segment elevation acute coronary syndrome; $\mathrm{PCl}$, percutaneous coronary intervention; STEMI, ST-segment elevation myocardial infarction. 
Braunwald classification type 3 without elevation of cardiac biomarkers. Experienced clinical research coordinators from the independent clinical research organisation (Research Institute for Production Development, Kyoto, Japan; online supplemental appendix B) collected data on baseline clinical, angiographic and procedural characteristics from the hospital charts or hospital databases according to the prespecified definitions that were identical in Cohort-2 and Cohort-3.

The primary outcome measure of this study was allcause death at 3 years. The secondary outcome measures included cardiovascular death, cardiac death, sudden cardiac death, non-cardiovascular death, non-cardiac death, myocardial infarction, definite stent thrombosis, stroke, hospitalisation for heart failure, major bleeding, any coronary revascularisation and target vessel revascularisation. The definition of baseline characteristics and endpoints were described in online supplemental appendix C.

\section{Data collection and follow-up}

Collection of follow-up information was mainly conducted through review of hospital charts by the clinical research coordinators, and additional follow-up information was collected through contact with patients, relatives and/ or referring physicians by sending mail with questions regarding vital status, subsequent hospitalisations and status of antiplatelet therapy.

Given the difference of follow-up durations between the two cohorts, follow-up was censored at 3 years after the index procedure to ensure $>90 \%$ of clinical follow-up rate in both cohorts. Complete 3-year follow-up information was obtained for $95.9 \%$ of patients in Cohort-2 and $93.5 \%$ in Cohort-3, respectively. The clinical event committee adjudicated those endpoint events including death, myocardial infarction, stroke and major bleeding (online supplemental appendix D).

\section{Statistical analysis}

Continuous variables were expressed as mean $\pm \mathrm{SD}$ or median with IQR. We used the Student's t-test or Wilcoxon rank-sum test based on their distributions for comparing continuous variables. Categorical variables were expressed as frequencies and percentages and were compared using $\chi^{2}$ test. We estimated cumulative incidence by the Kaplan-Meier method and assess the differences with the log-rank test. To estimate the adjusted HR and the 95\% CI of Cohort-3 compared with Cohort-2, we used multivariable Cox proportional hazard models by incorporating the 16 clinically relevant factors. Clinically relevant factors were age $\geq 75$ years, sex, body mass index $<25.0 \mathrm{~kg} / \mathrm{m}^{2}$, hypertension, diabetes mellitus, current smoking, heart failure, prior myocardial infarction, prior stroke, peripheral vascular disease, estimated glomerular filtration rate (eGFR) $<30 \mathrm{~mL} / \mathrm{min} / 1.73 \mathrm{~m}^{2}$ without haemodialysis, haemodialysis, anaemia, malignancy, target of proximal left anterior descending coronary artery and PCI strategy (table 1). The risk-adjusting variables included demographic factors, but not included the factors related to management during the index hospitalisation, because differences in management converged into the changes between Cohort-2 and Cohort-3. Continuous riskadjusting variables were dichotomised according to the clinically meaningful reference values to make proportional hazard assumptions robust and to be consistent with previous reports. ${ }^{7}$ Proportional hazard assumptions for the risk-adjusting variables were assessed on the plots of $\log ($ time $)$ versus $\log [-\log$ (survival) $]$ stratified by the variable, and the assumptions were verified to be acceptable for all variables. We conducted a landmark analysis for all-cause death within and beyond 30 days after the index procedure to distinguish early death related to the index NSTEACS event from late death during longterm follow-up. We also conducted a landmark analysis for major bleeding within and beyond 30 days to distinguish periprocedural bleeding from non-periprocedural bleeding. We also evaluated the cumulative incidence of major bleeding and persistent dual antiplatelet therapy (DAPT) discontinuation only in patients who received PCI as the index coronary revascularisation procedure.

All analyses were performed using R V.3.6.1 (R Foundation for Statistical Computing, Vienna, Austria). All reported $p$ values were two-tailed, and $p$ values less than 0.05 were considered statistically significant.

\section{Patient and public involvement}

In this study, patients were not involved in the design, or conduct, or reporting or dissemination plans of our research.

\section{RESULTS \\ Baseline characteristics and medications}

The prevalence of NSTEMI among NSTEACS was significantly higher in Cohort-3 compared with Cohort-2 (table 1). Baseline clinical characteristics were generally similar between the two cohorts except for a few aspects. Patients in Cohort-3 were older and more often had heart failure and malignancy, but less often had current smoking and prior myocardial infarction than those in Cohort-2 (table 1). Regarding procedural characteristics, the prevalence of emergency procedures, transradial approach and intravascular ultrasound (IVUS) use increased significantly from Cohort-2 to Cohort-3. The prevalence of DES use was much higher in Cohort-3 than in Cohort-2, with new-generation DES use in the vast majority of DES cases in Cohort-3 (table 1). In terms of baseline medications, patients in Cohort-3 more often took thienopyridine, statins, beta-blockers, ACE inhibitors/angiotensin receptor blockers and proton pump inhibitors than those in Cohort-2. Thienopyridines used in the vast majority of patients were ticlopidine in Cohort-2 and clopidogrel in Cohort-3 (table 1). 
Table 1 Baseline characteristics of patients with NSTEACS comparing Cohort-2 and Cohort-3

\begin{tabular}{|c|c|c|c|}
\hline & $\begin{array}{l}\text { Cohort-2 } \\
(\mathrm{N}=1683)\end{array}$ & $\begin{array}{l}\text { Cohort-3 } \\
(\mathrm{N}=1571)\end{array}$ & $P$ value \\
\hline NSTEMI & $703(42 \%)$ & $1329(85 \%)$ & $<0.001$ \\
\hline UA & $980(58 \%)$ & $242(15 \%)$ & \\
\hline \multicolumn{4}{|l|}{ (A) Clinical characteristics } \\
\hline Age (years) & $68.9 \pm 11.4$ & $69.8 \pm 11.6$ & 0.02 \\
\hline Age $\geq 75$ years $^{*}$ & $589(35 \%)$ & $594(38 \%)$ & 0.10 \\
\hline Men $^{*}$ & $1207(72 \%)$ & $1167(74 \%)$ & 0.11 \\
\hline Body mass index $\left(\mathrm{kg} / \mathrm{m}^{2}\right)$ & $23.5 \pm 3.4$ & $23.7 \pm 3.6$ & 0.07 \\
\hline Body mass index $<25.0 \mathrm{~kg} / \mathrm{m}^{2 \star}$ & $1186(70 \%)$ & $1078(69 \%)$ & 0.27 \\
\hline Hypertension* & $1385(82 \%)$ & $1303(83 \%)$ & 0.66 \\
\hline Systolic blood pressure on admission & $140 \pm 28$ & $140 \pm 29$ & 0.62 \\
\hline Diastolic blood pressure on admission & $78 \pm 19$ & $79 \pm 19$ & 0.07 \\
\hline Diabetes mellitus* & $640(38 \%)$ & $569(36 \%)$ & 0.30 \\
\hline On insulin therapy & $119(7.1 \%)$ & $102(6.5 \%)$ & 0.56 \\
\hline Current smoking* & $608(36 \%)$ & $484(31 \%)$ & 0.002 \\
\hline Heart failure* & $384(23 \%)$ & $428(27 \%)$ & 0.004 \\
\hline Current heart failure & $354(21 \%)$ & $411(26 \%)$ & $<0.001$ \\
\hline LVEF & $57.5 \pm 13$ & $57.9 \pm 13$ & 0.41 \\
\hline LVEF $\leq 40 \%$ & $138(12 \%)$ & $134(10 \%)$ & 0.12 \\
\hline Prior myocardial infarction* & $123(7.3 \%)$ & $60(3.8 \%)$ & $<0.001$ \\
\hline Prior stroke (symptomatic) ${ }^{*}$ & $209(12 \%)$ & $219(14 \%)$ & 0.22 \\
\hline Peripheral vascular disease* & $76(4.5 \%)$ & $67(4.3 \%)$ & 0.79 \\
\hline eGFR $<30 \mathrm{~mL} / \mathrm{min} / 1.73 \mathrm{~m}^{2}$, without haemodialysis* & $89(5.3 \%)$ & $98(6.2 \%)$ & 0.28 \\
\hline Haemodialysis* & $59(3.5 \%)$ & $68(4.3 \%)$ & 0.26 \\
\hline ESRD (eGFR $<30 \mathrm{~mL} / \mathrm{min} / 1.73 \mathrm{~m}^{2}$ or haemodialysis) & $148(8.8 \%)$ & $166(11 \%)$ & 0.10 \\
\hline Atrial fibrillation & $156(9.3 \%)$ & $154(9.8 \%)$ & 0.65 \\
\hline Anaemia (haemoglobin $<11.0 \mathrm{~g} / \mathrm{dL})^{\star}$ & $240(14 \%)$ & $214(14 \%)$ & 0.64 \\
\hline Thrombocytopenia (platelet $<100000$ ) & $31(1.8 \%)$ & $36(2.3 \%)$ & 0.44 \\
\hline Chronic obstructive pulmonary disease & $69(4.1 \%)$ & $59(3.8 \%)$ & 0.68 \\
\hline Liver cirrhosis & $43(2.6 \%)$ & $35(2.2 \%)$ & 0.62 \\
\hline Malignancy* & $146(8.7 \%)$ & $179(11 \%)$ & 0.01 \\
\hline ARC-HBR & $773(46 \%)$ & $748(48 \%)$ & 0.35 \\
\hline \multicolumn{4}{|l|}{ (B) Angiographic characteristics } \\
\hline No of target lesions or anastomoses & $1.7 \pm 1.0$ & $1.7 \pm 1.0$ & 0.20 \\
\hline Multivessel disease & $1016(60 \%)$ & $939(60 \%)$ & 0.76 \\
\hline Target of proximal LAD* & 949 (56\%) & $913(58 \%)$ & 0.34 \\
\hline \multicolumn{4}{|l|}{ (C) Procedural characteristic } \\
\hline Emergency procedure $†$ & $1110(66 \%)$ & $1156(74 \%)$ & $<0.001$ \\
\hline $\mathrm{PCl}^{*}$ & $1453(86 \%)$ & $1440(92 \%)$ & $<0.001$ \\
\hline Transradial approach & $262(18 \%)$ & $438(30 \%)$ & $<0.001$ \\
\hline Transfemoral approach & $1035(71 \%)$ & $913(63 \%)$ & $<0.001$ \\
\hline IVUS use & $494(34 \%)$ & $981(68 \%)$ & $<0.001$ \\
\hline Staged PCl & 333 (23\%) & 339 (24\%) & 0.72 \\
\hline Stent use & 1348 (93\%) & $1356(94 \%)$ & 0.13 \\
\hline Bare metal stent & 699 (52\%) & $320(24 \%)$ & $<0.001$ \\
\hline
\end{tabular}


Table 1 Continued

\begin{tabular}{|c|c|c|c|}
\hline & $\begin{array}{l}\text { Cohort-2 } \\
(\mathrm{N}=1683)\end{array}$ & $\begin{array}{l}\text { Cohort-3 } \\
(\mathrm{N}=1571)\end{array}$ & $P$ value \\
\hline Drug-eluting stent & $649(48 \%)$ & $1036(76 \%)$ & $<0.001$ \\
\hline First-generation DES use & $649(100 \%)$ & $19(1.8 \%)$ & $<0.001$ \\
\hline Sirolimus-eluting stent (CYPHER) & $614(95 \%)$ & $14(74 \%)$ & - \\
\hline Paclitaxel-eluting stent (TAXUS) & $46(7.1 \%)$ & $5(26 \%)$ & - \\
\hline New-generation DES use & - & $1026(99 \%)$ & - \\
\hline Everolimus-eluting stent (XIENCE) & - & $584(57 \%)$ & - \\
\hline Everolimus-eluting stent (PROMUS) & - & $232(23 \%)$ & - \\
\hline Biolimus-eluting stent (NOBORI) & - & $251(24 \%)$ & - \\
\hline Zotarolimus-eluting stent (RESOL) & - & $24(2.3 \%)$ & - \\
\hline Zotarolimus-eluting stent (ENDEAVOR) & - & $98(9.6 \%)$ & - \\
\hline CABG & $230(14 \%)$ & $131(8.3 \%)$ & $<0.001$ \\
\hline Off pump & $118(51 \%)$ & $64(49 \%)$ & 0.65 \\
\hline ITA use & $217(94 \%)$ & $121(92 \%)$ & 0.46 \\
\hline \multicolumn{4}{|l|}{ (D) Medication at hospital discharge } \\
\hline \multicolumn{4}{|l|}{ Antiplatelet therapy } \\
\hline Thienopyridine & $1439(86 \%)$ & $1457(93 \%)$ & $<0.001$ \\
\hline Ticlopidine & $1300(91 \%)$ & $38(2.7 \%)$ & \\
\hline Clopidogrel & 127 (8.9\%) & $1389(97 \%)$ & \\
\hline Aspirin & $1662(99 \%)$ & $1544(98 \%)$ & 0.33 \\
\hline Cilostazol & $404(24 \%)$ & $45(2.9 \%)$ & $<0.001$ \\
\hline Statins & $811(48 \%)$ & $1229(78 \%)$ & $<0.001$ \\
\hline High-intensity statins therapy $\ddagger$ & $26(1.5 \%)$ & $29(1.8 \%)$ & 0.60 \\
\hline Beta-blockers & $493(29 \%)$ & $678(43 \%)$ & $<0.001$ \\
\hline ACE inhibitor/ARB & $969(58 \%)$ & $1052(67 \%)$ & $<0.001$ \\
\hline Nitrates & $657(39 \%)$ & $290(18 \%)$ & $<0.001$ \\
\hline Calcium channel blockers & $643(38 \%)$ & $547(35 \%)$ & 0.049 \\
\hline Nicorandil & $461(27 \%)$ & $296(19 \%)$ & $<0.001$ \\
\hline Warfarin & $166(9.9 \%)$ & $162(10 \%)$ & 0.71 \\
\hline DOAC & - & $24(1.5 \%)$ & - \\
\hline Proton pump inhibitors & $581(35 \%)$ & $1089(69 \%)$ & $<0.001$ \\
\hline Histamine type-2 receptor blockers & $465(28 \%)$ & $211(13 \%)$ & $<0.001$ \\
\hline
\end{tabular}

Continuous variables were expressed as mean \pm SD or median (IQR). Categorical variables were expressed as number (percentage). Number of missing values were described in online supplemental appendix $\mathrm{E}$.

${ }^{*}$ Risk-adjusting variables for the Cox proportional hazard models.

†Emergency procedure was defined as the procedure which was performed on the index admission date for patients with acute myocardial infarction and/or the procedure which was recorded as emergency procedure through review of hospital charts.

¥High-intensity statin therapy in this study was defined as the statin doses greater than or equal to atorvastatin $20 \mathrm{mg}$, pitavastatin $4 \mathrm{mg}$ or rosuvastatin $10 \mathrm{mg}$.

ARC-HBR, Academic Research Consortium-High Bleeding Risk; CABG, coronary artery bypass grafting; DOAC, direct oral anticoagulants; eGFR, estimated glomerular filtration rate; ESRD, end-stage renal disease; ACE inhibitor/ARB, angiotensin-converting enzyme inhibitor/ angiotensin II receptor blocker; ITA, internal thoracic artery; LAD, left anterior descending coronary artery ; NSTEACS, non-ST-segment elevation acute coronary syndrome; $\mathrm{PCl}$, percutaneous coronary intervention.

\section{Clinical outcomes}

The cumulative 3-year incidence of all-cause death was not significantly different between Cohort-2 and Cohort-3 $(13.1 \%$ and $13.8 \%$, log-rank $\mathrm{p}=0.50$ ) (table 2 and figure 2A). After adjusting for confounders, the risk of all-cause death in Cohort-3 relative to Cohort-2 remained insignificant at 3 years (HR 1.00, 95\% CI 0.83 to 1.22, $\mathrm{p}=0.97$ ) (table 2). In the 30-day landmark analysis, cumulative incidence of all-cause death was also not significantly different between Cohort-2 and Cohort-3, both within 30 
Table 2 Clinical outcomes compared between Cohort-2 and Cohort-3

\begin{tabular}{|c|c|c|c|c|c|c|}
\hline \multirow[b]{3}{*}{ Endpoints } & $\begin{array}{l}\text { Cohort-2 } \\
(\mathrm{N}=1683)\end{array}$ & $\begin{array}{l}\text { Cohort-3 } \\
(\mathrm{N}=1571)\end{array}$ & \multirow[b]{3}{*}{ Crude HR $(95 \% \mathrm{Cl})$} & \multirow[b]{3}{*}{$P$ value } & \multirow[b]{3}{*}{ Adjusted HR $(95 \% \mathrm{Cl})$} & \multirow[b]{3}{*}{$P$ value } \\
\hline & \multicolumn{2}{|c|}{ Number of patients with event } & & & & \\
\hline & \multicolumn{2}{|c|}{ (Cumulative 3-year incidence) } & & & & \\
\hline All-cause death & $216(13.1 \%)$ & 210 (13.8\%) & $1.07(0.88$ to 1.29$)$ & 0.5 & 1.00 (0.83 to 1.22$)$ & 0.97 \\
\hline Cardiovascular death & $140(8.6 \%)$ & $125(8.3 \%)$ & 0.98 (0.77 to 1.24$)$ & 0.85 & 0.91 (0.71 to 1.16$)$ & 0.43 \\
\hline Cardiac death & $126(7.7 \%)$ & $114(7.5 \%)$ & 0.99 (0.77 to 1.27$)$ & 0.94 & 0.91 (0.70 to 1.18$)$ & 0.48 \\
\hline Sudden cardiac death & $17(1.1 \%)$ & $19(1.4 \%)$ & 1.23 (0.64 to 2.37$)$ & 0.53 & - & - \\
\hline $\begin{array}{l}\text { Non-cardiovascular } \\
\text { death }\end{array}$ & $76(4.9 \%)$ & $85(6.1 \%)$ & 1.23 (0.91 to 1.68$)$ & 0.18 & $1.17(0.85$ to 1.60$)$ & 0.33 \\
\hline Non-cardiac death & $90(5.8 \%)$ & $96(6.8 \%)$ & 1.18 (0.88 to 1.57$)$ & 0.27 & 1.13 (0.84 to 1.52$)$ & 0.41 \\
\hline Myocardial infarction & $56(3.6 \%)$ & $57(4.0 \%)$ & 1.12 (0.77 to 1.62$)$ & 0.55 & 1.09 (0.75 to 1.59$)$ & 0.65 \\
\hline $\begin{array}{l}\text { Definite stent } \\
\text { thrombosis* }\end{array}$ & $21(1.7 \%)$ & $6(0.5 \%)$ & 0.29 (0.11 to 0.67$)$ & 0.003 & - & - \\
\hline Stroke & $90(5.8 \%)$ & $54(3.8 \%)$ & 0.65 (0.47 to 0.91$)$ & 0.01 & 0.65 (0.46 to 0.92$)$ & 0.02 \\
\hline $\begin{array}{l}\text { Hospitalisation for } \\
\text { heart failure }\end{array}$ & $119(7.7 \%)$ & $94(6.7 \%)$ & 0.86 (0.66 to 1.13$)$ & 0.28 & $0.82(0.62$ to 1.08$)$ & 0.16 \\
\hline Major bleeding & $315(19.1 \%)$ & $300(19.7 \%)$ & 1.02 (0.87 to 1.20$)$ & 0.79 & 1.25 (1.06 to 1.47$)$ & 0.008 \\
\hline $\begin{array}{l}\text { Any coronary } \\
\text { revascularisation }\end{array}$ & 458 (29.4\%) & $353(24.9 \%)$ & 0.81 (0.70 to 0.93$)$ & 0.003 & 0.76 (0.66 to 0.87$)$ & $<0.001$ \\
\hline $\begin{array}{l}\text { Target vessel } \\
\text { revascularisation }\end{array}$ & $351(22.4 \%)$ & $255(18.0 \%)$ & 0.76 (0.65 to 0.90$)$ & 0.001 & 0.71 (0.60 to 0.84$)$ & $<0.001$ \\
\hline
\end{tabular}

The risk of Cohort-3 relative to Cohort-2 was expressed as HR with 95\% Cl. The covariates for the multivariate Cox proportional hazard models were indicated in table 1. Myocardial infarction was adjudicated based on the ARTS definition.

Major bleeding was defined as GUSTO moderate/severe bleeding.

*Definite stent thrombosis was adjudicated based on the ARC definition and was analysed only for patients who underwent PCI with stent implantation (1348 patients in Cohort-2 and 1356 patients in Cohort-3).

ARC, Academic Research Consortium; ARTS, arterial revascularisation therapy study; GUSTO, Global Utilisation of Streptokinase and Tissue plasminogen activator for Occluded coronary arteries; NSTEACS, non-ST-segment elevation acute coronary syndrome.

days $(2.9 \%$ vs $3.5 \%$, log-rank $\mathrm{p}=0.27)$ and beyond 30 days $(10.5 \%$ vs $10.7 \%$, log-rank $\mathrm{p}=0.88)$. The risk of Cohort- 3 relative to Cohort-2 remained insignificant both within 30 days (HR 1.02, 95\% CI 0.68 to $1.52, \mathrm{p}=0.92$ ) and beyond 30 days (HR $0.99,95 \%$ CI 0.80 to $1.24, \mathrm{p}=0.96$ ) (online supplemental figure 1). There also was no difference in other mortality outcomes such as cardiovascular and noncardiovascular death between the two cohorts (table 2 and figure 2B). The cumulative 3-year incidence was significantly lower in Cohort 3 than in Cohort-2 for definite stent thrombosis $(1.7 \%$ vs $0.5 \%, \log$-rank $\mathrm{p}=0.004)$, stroke $(5.8 \%$ vs $3.8 \%$, log-rank $\mathrm{p}=0.01)$, target vessel revascularisation $(22.4 \%$ vs $18.0 \%$, log-rank $\mathrm{p}=0.001)$ and any coronary revascularisation $(29.4 \%$ vs $24.9 \%$, log-rank $\mathrm{p}=0.003$ ), while it was not different for myocardial infarction between Cohort-2 and Cohort-3 (3.6\% vs 4.0\%, logrank $\mathrm{p}=0.55$ ) (table 2 and figure 3 ). Even after adjusting for confounders, the lower risk of Cohort-3 relative to Cohort-2 remained significant for stroke (HR 0.65, 95\% CI 0.46 to $0.92, \mathrm{p}=0.02$ ), any coronary revascularisation (HR $0.76,95 \%$ CI 0.66 to $0.87, \mathrm{p}<0.001$ ) and target vessel revascularisation (HR $0.71,95 \%$ CI 0.60 to $0.84, \mathrm{p}<0.001$ ), but not for myocardial infarction (HR 1.09, 95\% CI 0.75 to $1.59, \mathrm{p}=0.65$ ) (table 2).

The cumulative incidence of major bleeding was not significantly different between Cohort-2 and Cohort-3 $(19.1 \%$ and $19.7 \%$, log-rank $\mathrm{p}=0.78$ ) (table 2 and figure 3). However, after adjusting for confounders, the excess risk of Cohort-3 relative to Cohort- 2 turned out to be significant for major bleeding (HR 1.25, 95\% CI 1.06 to $1.47, \mathrm{p}=0.008$ ) (table 2 ). In the 30-day landmark analysis, there was a trend towards increased adjusted risk of Cohort-3 relative to Cohort-2 for major bleeding both within 30 days and beyond 30 days (online supplemental figure 2). Considering the differences in the patterns of major bleeding between PCI and CABG, we evaluated the risk of major bleeding only in patients who received PCI; the cumulative incidence of major bleeding was significantly higher in Cohort-3 compared with Cohort-2, and after adjusting confounders, the excess risk of Cohort-3 relative to Cohort-2 remained significant for major bleeding (online supplemental figure 3). These results were consistent in both within and beyond 30 days after index procedure (online supplemental figure 3). The 


\section{A All-cause death}

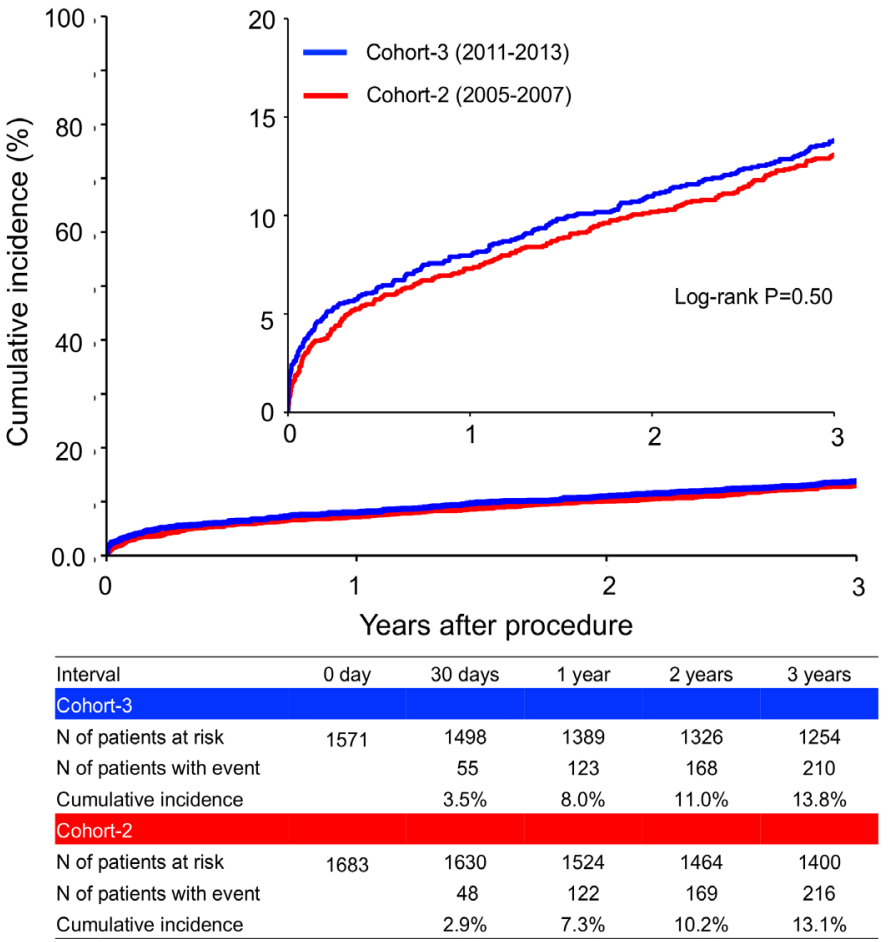

B Cardiovascular death

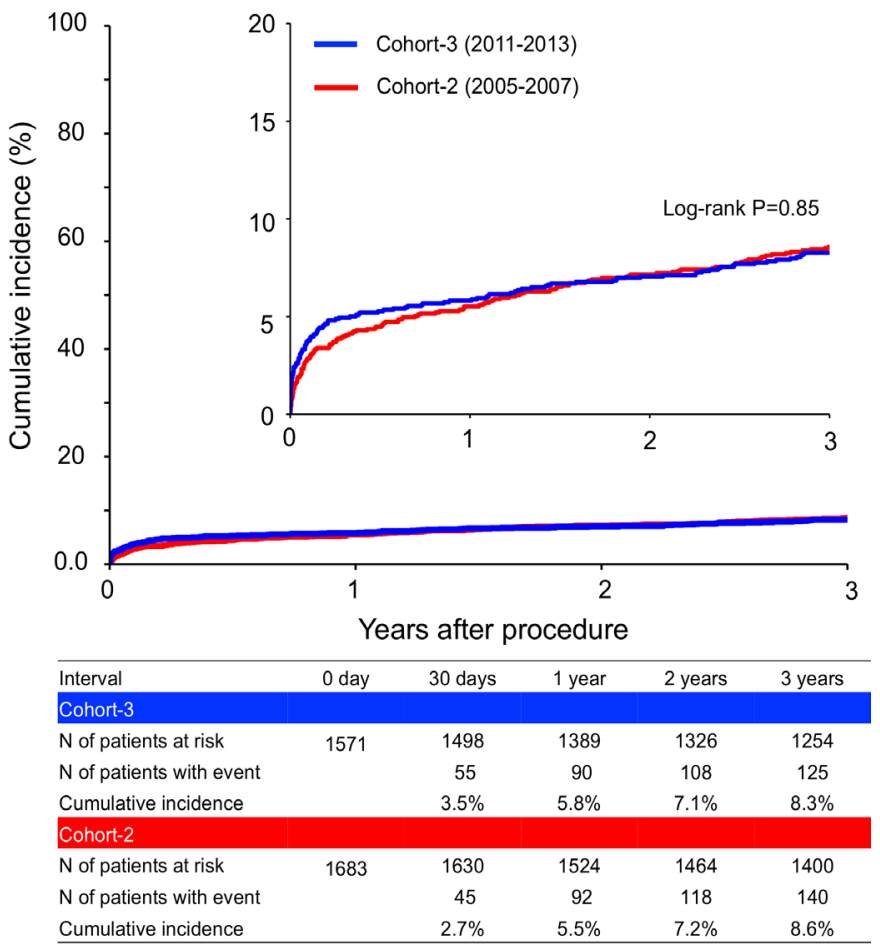

Figure 2 Kaplan-Meier curves comparing mortality outcomes between Cohort-2 and Cohort-3: (A) all-cause death and (B) cardiovascular death.

cumulative incidence of persistent DAPT discontinuation in patients who received PCI was significantly lower in Cohort-3 than in Cohort-2, indicating significantly longer DAPT duration in Cohort-3 than in Cohort-2 (online supplemental figure 4 ).

\section{DISCUSSION}

The main findings of this study were as follows: (1) Patients with NSTEACS in Cohort-3 were older and more often had heart failure than those in Cohort-2. (2) The prevalence of PCI, emergency procedure, transradial approach, DES use, IVUS use and guideline-directed medical therapy were higher with longer duration of DAPT in Cohort-3 than in Cohort-2. (3) There was no change in 3-year mortality risk from Cohort-2 to Cohort-3. (4) Patients in Cohort-3 as compared with those in Cohort-2 were associated with lower risks for definite stent thrombosis, stroke and any coronary revascularisation, but with higher risk for major bleeding.

The American Heart Association (AHA)/American College of Cardiology (ACC) and European Society of Cardiology (ESC) guidelines have regularly updated and recommended appropriate interventional and pharmacological strategies. ${ }^{8-10}$ Several studies demonstrated the improvement of early and long-term outcome in patients with NSTEACS from 1990s to 2000s..$^{2-4}$ Meanwhile, there was little data which evaluated long-term clinical outcomes in patients with NSTEACS after 2010s, ${ }^{5}$ and it is unknown whether these guideline recommendations have led to an improvement of clinical outcomes. Given the higher risk of long-term mortality in patients with NSTEACS than in patients with STEMI, evaluating long-term clinical outcome and adherence to evidence-based practice in the real-world clinical practice would be important. Here, we evaluated long-term clinical outcomes in patients with NSTEACS enrolled between 2011 and 2013 and between 2005 and 2007 using a series of Japanese registry of consecutive patients who underwent first coronary revascularisation.

The proportion of NSTEMI among NSTEACS was much higher in Cohort-3 than in Cohort-2, which could be related to the fact that high sensitivity troponin measurement was introduced in Japan from 2010, and therefore, was not available in Cohort-2.

Nevertheless, patients in Cohort-3 were older and more often treated in emergency, and more often had current heart failure than those in Cohort-2. We observed substantial changes in practice patterns which might have contributed to improve clinical outcomes from Cohort-2 to Cohort-3. First, we demonstrated that more patients took guideline-directed medical therapy including a P2Y12 inhibitor, beta-blockers, ACE inhibitors and statins which were recommended by both the AHA/ACC and ESC guidelines. ${ }^{1810}$ Second, for patients who underwent PCI, more patients were treated with transradial approach, which was recommend in the ESC guideline because of lower risk of bleeding and a trend towards favourable outcomes. ${ }^{10} 11$ Third, much larger proportion of patients 


\section{A Definite stent thrombosis}

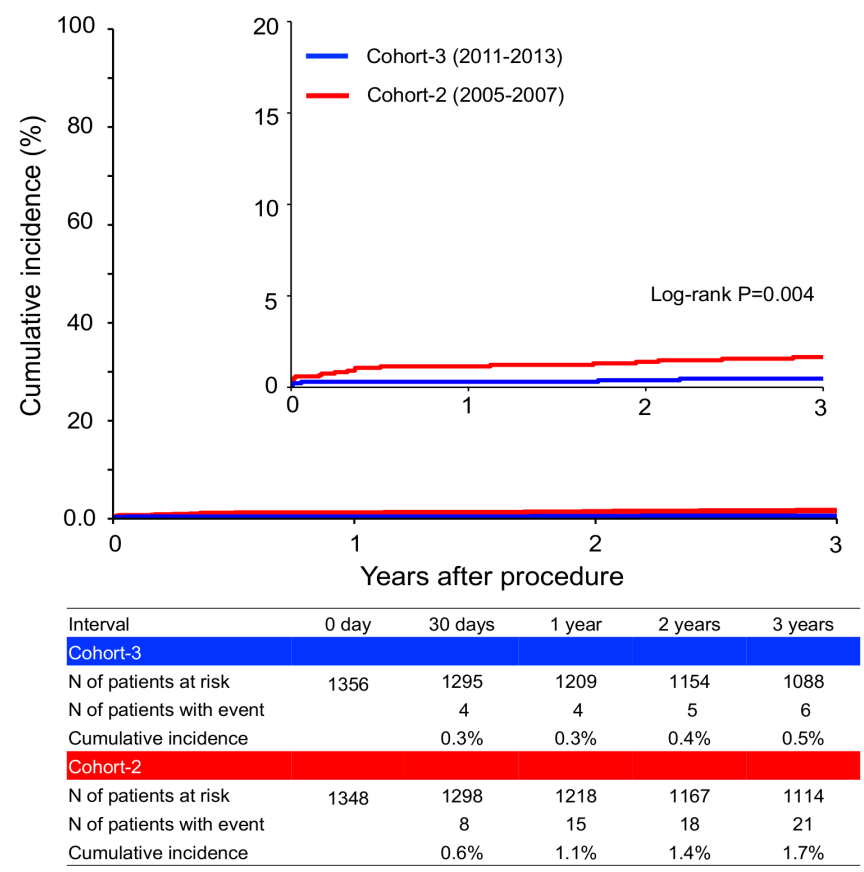

\section{Major bleeding}

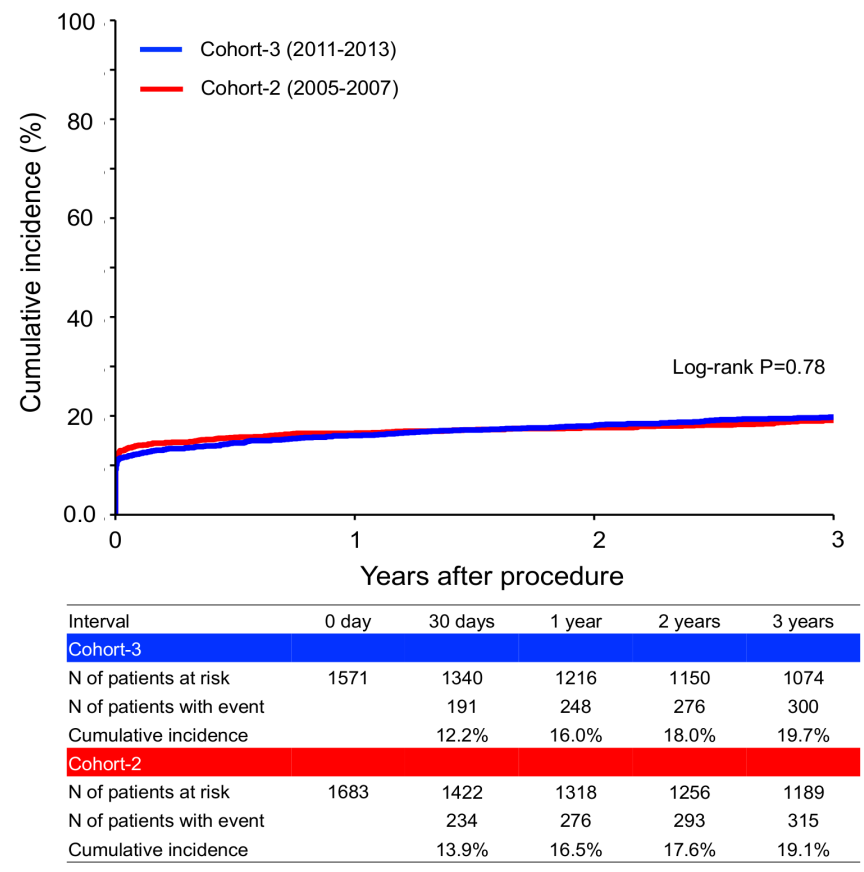

\section{B Stroke}

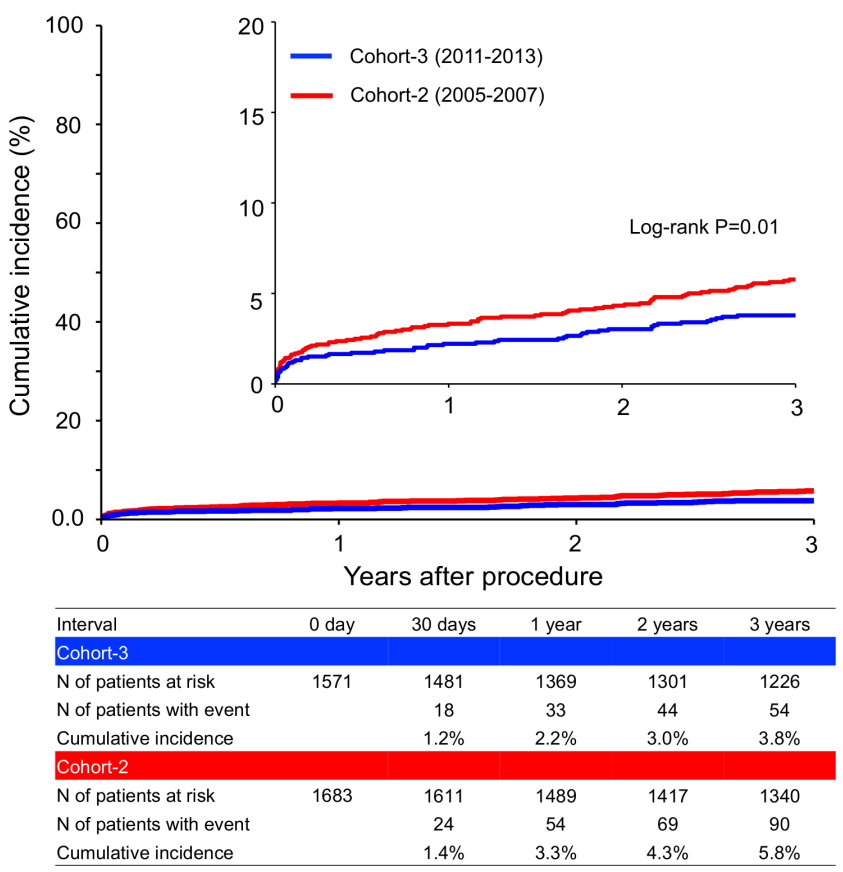

D Any coronary revascularization

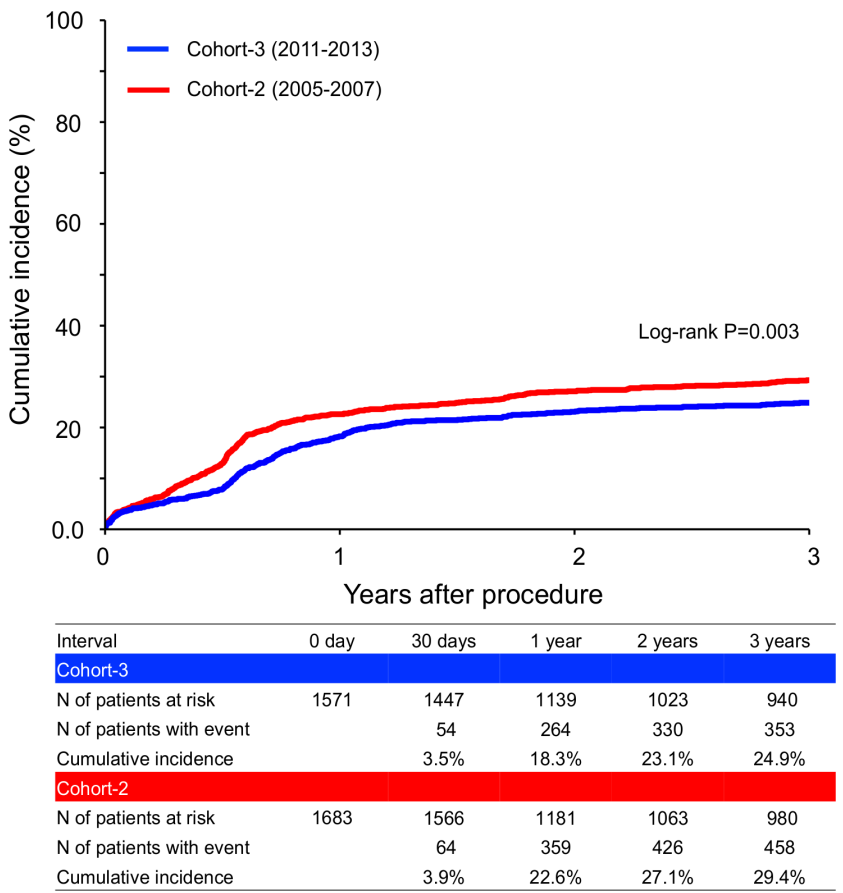

Figure 3 Kaplan-Meier curves comparing other secondary outcome measures between Cohort-2 and Cohort-3: (A) definite stent thrombosis, (B) stroke, (C) major bleeding and (D) any coronary revascularisation. Definite stent thrombosis was adjudicated based on the ARC definition and was analysed only for patients who underwent PCl with stent implantation (1348 patients in Cohort-2 and 1356 patients in Cohort-3). Major bleeding was defined as GUSTO moderate/severe bleeding. ARC, Academic Research Consortium; GUSTO, Global Utilisation of Streptokinase and Tissue plasminogen activator for Occluded coronary arteries.

were treated with DES, particularly new-generation DES, in Cohort-3 than in Cohort-2. Several randomised clinical trials and meta-analysis have demonstrated reduction in cardiovascular death or non-fatal MI with new-generation
DES compared with bare metal stent (BMS). ${ }^{12}{ }^{13}$ Fourth, more patients underwent IVUS-guided PCI which was reported to be associated with favourable outcomes compared with angio-guided PCI. ${ }^{14}$ Despite these changes 
in practice patterns, we could not demonstrate significant improvement in mortality outcomes from Cohort-2 to Cohort-3. Nevertheless, the adjusted risk for cardiac or cardiovascular death numerically favoured Cohort-3 relative to Cohort-2, although the present study was underpowered for the mortality outcomes. The changes in practice patterns from Cohort-2 to Cohort-3 might be qualitatively appropriate, but quantitatively insufficient. We should further promote guideline-directed medical therapy, high intensity statin therapy in particular, which might lead to improvement in mortality outcomes. Moreover, it might be important to minimise the difference in adherence to evidence-based practice across facilities. ${ }^{15} 16$

We demonstrated substantial reduction in stroke from Cohort-2 to Cohort-3, which could be partially explained by the higher prevalence of guideline-directed medical therapy. Control of blood pressure, which is crucial in preventing stroke, might have improved from Cohort-2 to Cohort-3, although we did not have data on blood pressure during follow-up. ${ }^{17}$ We also found significant reduction in the risks for definite stent thrombosis, and any coronary revascularisation from Cohort-3 to Cohort-2, which could mostly be explained by the more widespread use of DES and predominant use of new-generation DES in Cohort-3 than in Cohort-2, ${ }^{18}$ although we could not deny the contribution of the higher prevalence of guideline-directed medical therapy.

In the mean time, we observed the higher risk of bleeding in Cohort-3 relative to Cohort-2 in patients who underwent PCI. The reasons for the higher bleeding risk in Cohort-3 than in Cohort-2 were considered to be the difference in the types of thienopyridine used and longer DAPT duration in Cohort-3 than in Cohort-2. In Cohort-2, ticlopidine was predominantly used with a dose regimen of $100 \mathrm{mg}$ two times per day as the standard dose in Japan, which was much lower than the dose used globally (250 mg two times per day), while in Cohort-3, clopidogrel was predominantly used with a dose regimen of $75 \mathrm{mg}$ once daily which was the same dose as that used globally. Recently, several randomised trials have demonstrated very short DAPT after PCI reduced major bleeding without increase in cardiovascular events..$^{19} 20$ Given the ageing society with higher risk of bleeding, we should further explore the optimal DAPT duration and optimal maintenance antithrombotic regimen in patients with NSTEACS.

\section{Limitations}

This study has several limitations. First, historical comparison should result in systematic differences in selection of patients and acquisition of outcomes. To minimise this difference, we enrolled only patients from facilities that participated in both Cohort-2 and Cohort-3, standardised the follow-up duration at 3 years, and adopted the identical methodology for baseline and follow-up data collection and definitions of baseline characteristics and clinical outcome measures in Cohort-2 and Cohort-3. We found numerically higher risk for myocardial infarction in Cohort-3 than inCohort-2, despite significantly lower incidence of definite stent thrombosis in Cohort-3 than in Cohort-2. We could not deny the ascertainment bias for myocardial infarction. The less widespread use of troponin for the diagnosis of myocardial infarction in Cohort-2 compared with Cohort-3 might have underestimated the incidence of myocardial infarction as an outcome measure in Cohort-2. Second, changes in practice pattern beyond 2014 were not available and the present study results did not represent the contemporary clinical practice. Moreover, the thienopyridines used were mainly ticlopidine in Cohort-2 and mainly clopidogrel in Cohort-3, which was quite different from the current antiplatelet therapy (ticagrelor or prasugrel) in patients with NSTEACS. Third, we included only patients who had undergone first coronary revascularisation, which could be a selection bias in this study. Fourth, we did not have data on control of blood pressure during follow-up, which might have improved over time, leading to reduction of stroke from Cohort-2 to Cohort-3. Fifth, the present study was underpowered for mortality outcomes. Finally, although we made extensive statistical risk adjustment, there might be some residual unmeasured confounders, especially unnoticed changes between cohorts.

\section{CONCLUSIONS}

In the past two decades, we did not find any significant difference in mortality outcomes in patients with NSTEACS. We observed significant reduction in the risks for definite stent thrombosis, stroke and any coronary revascularisation, but significant increase in the risk for major bleeding.

\section{Author affiliations}

${ }^{1}$ Department of Cardiovascular Medicine, Graduate School of Medicine, Kyoto University, Kyoto, Japan

${ }^{2}$ Department of Clinical Epidemiology, Hyogo College of Medicine, Nishinomiya, Hyogo, Japan

${ }^{3}$ Department of Cardiology, Hyogo Prefectural Amagasaki Hospital, Amagasaki, Hyogo, Japan

${ }^{4}$ Division of Cardiology, Kokura Memorial Hospital, Kitakyushu, Fukuoka, Japan ${ }^{5}$ Department of Cardiovascular Medicine, Juntendo University Shizuoka Hospital, Izunokuni, Shizuoka, Japan

${ }^{6}$ Cardiovascular Center, The Tazuke Kofukai Medical Research Institute, Kitano Hospital, Osaka, Japan

${ }^{7}$ Department of Cardiology, Koto Memorial Hospital, Higashiomi, Shiga, Japan ${ }^{8}$ Division of Cardiology, Kinki University School of Medicine Nara Hospital, Ikoma, Nara, Japan

${ }^{9}$ Department of Cardiovascular Medicine, Kobe City Medical Center General Hospital, Kobe, Hyogo, Japan

${ }^{10}$ Department of Cardiovascular Medicine, Kansai Denryoku Hospital, Osaka, Japan ${ }^{11}$ Department of Cardiovascular Medicine, Osaka Red Cross Hospital, Osaka, Japan

${ }^{12}$ Department of Cardiology, Shizuoka City Shizuoka Hospital, Shizuoka, Japan

${ }^{13}$ Department of Cardiovascular Medicine, Hamamatsu Rosai Hospital, Hamamatsu,

Shizuoka, Japan

${ }^{14}$ Department of Cardiovascular Medicine, Shiga University of Medical Science, Otsu, Shiga, Japan

${ }^{15}$ Department of Cardiology, Japanese Red Cross Wakayama Medical Center, Wakayama, Japan

${ }^{16}$ Department of Cardiology, Mitsubishi Kyoto Hospital, Kyoto, Japan

${ }^{17}$ Department of Cardiology, Shizuoka General Hospital, Shizuoka, Japan 
${ }^{18}$ Division of Cardiovascular surgery, Kokura Memorial Hospital, Kitakyushu, Fukuoka, Japan

${ }^{19}$ Department of Cardiology, Kurashiki Central Hospital, Kurashiki, Okayama, Japan

${ }^{20}$ Department of Cardiovascular Surgery, Kurashiki Central Hospital, Kurashiki,

Okayama, Japan

${ }^{21}$ Department of Cardiovascular Surgery, Graduate School of Medicine, Kyoto University, Kyoto, Japan

Acknowledgements We appreciate the support and collaboration of the coinvestigators participating in the CREDO Kyoto PCI/CABG Registry Cohort-2 and the CREDO Kyoto PCI/CABG Registry Cohort-3.

Contributors T Kimura conceptualised the CREDO-Kyoto PCI/CABG Registry Cohort-3. YT prepared the original draft of the manuscript. H Shiomi, TM and T Kimura reviewed and edited the original draft of the manuscript. YT, H Shiomi, $Y$ Yoshikawa, YMN, K Yamamoto and K Yamaji curated the data. YT, TM and T Kimura constructed the methodology for this study. YT and TM performed the statistical analysis. H Shiomi, TM, RT, K Yamaji, JT, SS, MI, T Takeda, MS, NE, Kl, TI, TO, ES TY, T Tamura, H Sakamoto, KA, YS, YF, YS, YN, KK, T Komiya, KM and T Kimura are investigators of the CRED0-Kyoto PCI/CABG Registry Cohort-3. YT, H Shiomi, YY, YMN, K Yamamoto and KN assessed and validated events within the CREDO-Kyoto PCI/CABG Registry Cohort-3. T Kimura is the guarantor.

Funding This study was supported by an educational grant from the Research Institute for Production Development (Kyoto, Japan) and the Pharmaceuticals and Medical Devices Agency (PMDA) in Japan (Tokyo, Japan). Grant numbers were not applicable.

Competing interests HS reports personal fees from Abbott Vascular, Boston Scientific and Daiichi Sankyo. TM reports lecturer's fees from Bayer, Daiichi Sankyo, Japan Lifeline, Kyocera, Mitsubishi Tanabe, Novartis and Toray; the manuscript fees from Bristol-Myers Squibb and Kowa; served advisory boards for Asahi Kasei, Boston Scientific, Bristol-Myers Squibb and Sanofi. NE reports personal fees from Abbott Vascular, Medtronic, Terumo, Bayer, Boston Scientific, Daiichi-Sankyo, Edwards Lifescience, Pfizer, Bristol Myers Squibb, Takeda and Boehringer Ingelheim. YF reports personal fees from Daiichi Sankyo, Bayer, Sanofi, Kowa, Pfizer, Bristol-Myers Squibb, Otsuka Parmaceutical, Sumitomo Dainippon Pharma, Takeda and Ono Pharmaceutical. YN reports grant from Abbott Vascular and Boston Scientific, and reports personal fees from Abbott Vascular, Bayer, Boston Scientific, Bristol-Myers Squibb, Daiichi Sankyo. TK reports personal fees from Abbott Vascular, MSD, Eisai, Edwards Lifescience, Ono Pharmaceutical, Tsumura, Medical Review, Kowa, Sanofi, Daiichi Sankyo, Takeda Pharmaceutical, Pharmaceuticals and Medical Devices Agency, Abiomed, Bayer, Bristol-Myers Squibb, Boston Scientific, Lifescience, Toray, Astellas Amgen Biopharma, Astellas, AstraZeneca, Otsuka Parmaceutical, OrbusNeich, MSD Life Science Foundation, Public Health Research Foundation, Chugai Pharmaceutical, Boehringer Ingelheim, Japan Society for the Promotion of Science, Interscience, Philips, Kowa Pharmaceutical, Mitsubishi Tanabe Pharma, Terumo, Novartis Pharma and Sumitomo Dainippon Pharma.

Patient consent for publication Not required.

Ethics approval The protocol for CREDO Kyoto PCI/CABG Registry Cohort-2 and Cohort-3 were approved by the human research ethics committees of the Kyoto University Graduate School of Medicine (E42,E2400).

Provenance and peer review Not commissioned; externally peer reviewed.

Data availability statement All data relevant to the study are included in the article or uploaded as supplementary information.

Supplemental material This content has been supplied by the author(s). It has not been vetted by BMJ Publishing Group Limited (BMJ) and may not have been peer-reviewed. Any opinions or recommendations discussed are solely those of the author(s) and are not endorsed by BMJ. BMJ disclaims all liability and responsibility arising from any reliance placed on the content. Where the content includes any translated material, BMJ does not warrant the accuracy and reliability of the translations (including but not limited to local regulations, clinical guidelines, terminology, drug names and drug dosages), and is not responsible for any error and/or omissions arising from translation and adaptation or otherwise.

Open access This is an open access article distributed in accordance with the Creative Commons Attribution Non Commercial (CC BY-NC 4.0) license, which permits others to distribute, remix, adapt, build upon this work non-commercially, and license their derivative works on different terms, provided the original work is properly cited, appropriate credit is given, any changes made indicated, and the use is non-commercial. See: http://creativecommons.org/licenses/by-nc/4.0/.
ORCID iDs

Takeshi Morimoto http://orcid.org/0000-0002-6844-739X

Takeshi Kimura http://orcid.org/0000-0002-5665-4076

\section{REFERENCES}

1 Rodriguez F, Mahaffey KW. Management of patients with NSTE-ACS: a comparison of the recent AHA/ACC and ESC quidelines. J Am Coll Cardiol 2016;68:313-21.

2 Fox KAA, Steg PG, Eagle KA, et al. Decline in rates of death and heart failure in acute coronary syndromes, 1999-2006. JAMA 2007;297:1892-900.

3 Rogers WJ, Frederick PD, Stoehr E, et al. Trends in presenting characteristics and hospital mortality among patients with ST elevation and non-ST elevation myocardial infarction in the National Registry of myocardial infarction from 1990 to 2006. Am Heart $J$ 2008;156:1026-34.

4 Puymirat E, Schiele F, Steg PG, et al. Determinants of improved one-year survival in non-ST-segment elevation myocardial infarction patients: insights from the French FAST-MI program over 15 years. Int J Cardiol 2014;177:281-6.

5 Puymirat E, Simon T, Cayla G, et al. Acute myocardial infarction: changes in patient characteristics, management, and 6-month outcomes over a period of 20 years in the FAST-MI program (French registry of acute ST-elevation or non-ST-elevation myocardial infarction) 1995 to 2015. Circulation 2017;136:1908-19.

6 Kimura T, Morimoto T, Furukawa Y, et al. Long-term safety and efficacy of sirolimus-eluting stents versus bare-metal stents in real world clinical practice in Japan. Cardiovasc Interv Ther 2011;26:234-45.

7 Kimura T, Morimoto T, Furukawa Y, et al. Long-term outcomes of coronary-artery bypass graft surgery versus percutaneous coronary intervention for multivessel coronary artery disease in the bare-metal stent era. Circulation 2008;118:S199-209.

8 Amsterdam EA, Wenger NK, Brindis RG, et al. 2014 AHA/ACC guideline for the management of patients with non-ST-elevation acute coronary syndromes: a report of the American College of Cardiology/American heart association Task force on practice guidelines. J Am Coll Cardiol 2014;64:e139-228.

9 Jneid H, Addison D, Bhatt DL, et al. 2017 AHA/ACC clinical performance and quality measures for adults with ST-elevation and non-ST-elevation myocardial infarction: a report of the American College of Cardiology/American heart association Task force on performance measures. Circ Cardiovasc Qual Outcomes 2017;10.

10 Roffi M, Patrono C, Collet J-P, et al. 2015 ESC guidelines for the management of acute coronary syndromes in patients presenting without persistent ST-segment elevation: Task force for the management of acute coronary syndromes in patients presenting without persistent ST-segment elevation of the European Society of cardiology (ESC). Eur Heart J 2016;37:267-315.

11 Jolly SS, Yusuf S, Cairns J, et al. Radial versus femoral access for coronary angiography and intervention in patients with acute coronary syndromes (RIVAL): a randomised, parallel group, multicentre trial. Lancet 2011;377:1409-20.

12 Pedersen SH, Pfisterer M, Kaiser C, et al. Drug-eluting stents and bare metal stents in patients with NSTE-ACS: 2-year outcome from the randomised BASKET-PROVE trial. Eurolntervention 2014; 10:58-64.

13 Palmerini T, Benedetto U, Biondi-Zoccai G, et al. Long-term Safety of Drug-Eluting and Bare-Metal Stents: Evidence From a Comprehensive Network Meta-Analysis. J Am Coll Cardiol 2015:65:2496-507.

14 Zhang J, Gao X, Kan J, et al. Intravascular Ultrasound Versus Angiography-Guided Drug-Eluting Stent Implantation: The ULTIMATE Trial. J Am Coll Cardiol 2018;72:3126-37.

15 Mukherjee D, Fang J, Chetcuti S, et al. Impact of combination evidence-based medical therapy on mortality in patients with acute coronary syndromes. Circulation 2004;109:745-9.

16 Nallamothu B, Fox KAA, Kennelly BM, et al. Relationship of treatment delays and mortality in patients undergoing fibrinolysis and primary percutaneous coronary intervention. The global registry of acute coronary events. Heart 2007;93:1552-5.

17 Staessen JA, Wang JG, Thijs L. Cardiovascular protection and blood pressure reduction: a meta-analysis. Lancet 2001;358:1305-15.

18 Toyota T, Shiomi H, Morimoto T, et al. Meta-analysis of long-term clinical outcomes of everolimus-eluting stents. Am J Cardiol 2015;116:187-94.

19 Watanabe H, Domei T, Morimoto T, et al. Effect of 1-Month dual antiplatelet therapy followed by clopidogrel vs $12-$ month dual 
antiplatelet therapy on cardiovascular and bleeding events in patients receiving PCl: the STOPDAPT-2 randomized clinical trial. JAMA 2019;321:2414-27.
20 Mehran R, Baber U, Sharma SK, et al. Ticagrelor with or without aspirin in high-risk patients after PCl. N Engl J Med 2019;381:2032-42. 